\title{
The End of the Iraq War Offers Lessons for Withdrawal from Afghanistan
}

\author{
FOR RELEASE
}

Tuesday

November 5, 2013

Policymakers and military commanders should use the lessons derived from the final years of U.S. involvement in Iraq to inform critical decisions and timelines required to successfully end large-scale military operations, including the one in Afghanistan, according to a new RAND Corporation study.

It took approximately two years to wrap up the long-term, country-wide military presence in Iraq, which at its peak involved more than 170,000 troops, an equal number of contractors and more than 500 military bases and outposts.

What made this transition different from previous wars was that it marked a fundamental reorientation of the U.S. relationship with Iraq, said Richard R. Brennan Jr., lead author of the study and a senior political scientist with RAND, a nonprofit research organization. The final transition turned over all remaining U.S. military activities to the Government of Iraq, the U.S. Embassy in Baghdad and U.S. Central Command - or it terminated them.

A key finding of the RAND study is that almost nothing about the transition of responsibilities to the Iraqi government went as planned, mainly because most of the U.S. transition planning relied on assumptions and performance measures that proved overly optimistic. Transitions to the Iraqis also were affected by the dynamic internal security challenges in Iraq that required modification of security requirements and changes to performance goals.

The dangerous environment in Iraq required changes to key transition objectives and extensions in timelines. The transition also was dogged from the outset by the ambiguity of Iraqi and U.S. interest in a follow-on U.S. troop presence, as well as the specific missions such a presence would take on.

"From the very beginning, expectations of what the United States would be able to achieve in Iraq was probably greater than what was possible, given the time and resources available," Brennan said. "It is challenging to translate a broad political mission - 'produce a long-term and enduring strategic partnership between the United States and a sovereign, stable, and self-reliant Iraq that contributes to peace and security in the region' - into goals and objectives that are militarily achievable."

Despite political, operational, bureaucratic and fiscal challenges from both the U.S. and Iraqi sides, the United States did a number of things very well, Brennan said. For example, U.S. forces continued to train and assist Iraqi counterparts until the end of the mission, reinforcing 
professional relationships that had been developed over the previous eight years. The U.S. left behind an Iraqi army that had dramatically grown in both competency and professionalism.

The study concluded that, despite the difficulties, the U.S. Embassy in Baghdad was prepared to undertake its primary diplomatic missions when U.S. forces departed and, almost two years later, continues to manage a multi-faceted bilateral relationship that advances the shared interests of both nations. In the absence of a new agreement to maintain a residual military force in Iraq, the United States honored its commitment to make sure all forces departed Iraq by the end of 2011, an important goal from the standpoint of U.S.-Iraqi relations.

Policymakers and commanders in future transitions should resist the temptation to delay final decisions on ending operations to a point that a rapid pullout of troops creates a power vacuum. A more gradual exit of troops, contractors and equipment would not only have been more logistically manageable, but it might also have contributed to greater political stability in Iraq.

Planning should start by identifying U.S. strategic goals for the time period after the transition and, only then, consider how a civilian-led embassy could be set up. Well in advance of the departure of military forces, leaders should seek agreement with relevant congressional committees on the nature and likely cost of enduring civilian-led missions to protect U.S. interests, according to the report.

In any transition planning effort, an early commitment should be to work with the host nation to identify potential requirements and to reach firm agreements to cover the ongoing U.S. presence as well as its scope and functions. Agreements with the host government should be crafted that support continued operations that are consistent with Vienna Convention protocols that govern embassy operations worldwide.

Brennan said it also is important for military and civilian planners - both in the host nation and in Washington - to recognize that all of their goals may not be achieved at the end of the transition process. Planning should rigorously prioritize efforts in advance to set the critical conditions for the success of the organizations that will assume the military forces' responsibilities.

Brennan said civilian-military cooperation in Iraq was exceptionally good and was one of the main reasons the final transition went as well as it did. Effective transition planning must begin with seamless, top-level collaboration between the senior military and senior civilians in the host country, and pre-transition planning should be launched several years ahead of the transition deadline.

Although the U.S. will be able to use some of the lessons learned from Iraq in Afghanistan, Brennan cautioned that policymakers must recognize that there is no "one-size-fits-all" template to follow.

"In Iraq, the central government has the ability to exert control over most of the country and their military is a composite of society, with Kurds, Sunni and Shia (Muslims)," Brennan said. "In Afghanistan, much of the country is still ungovernable and the tribal leaders in the rural areas 
have an enormous amount of influence. Iraq has oil and an educated population and more opportunities for economic development than Afghanistan, which has fewer natural resources, more poverty and a less-educated population."

The RAND study covers the final 15 months of Operation New Dawn, ending with the disestablishment of United States Forces-Iraq and also describes events that occurred in the 12 months after the departure of U.S. Forces.

Research for the study was based on primary sources, including unclassified portions of plans, reports, assessments and briefings developed by U.S. Forces-Iraq and Embassy Baghdad, as well as numerous interviews with key personnel of the transition in Iraq. Brennan also served as a member of the Multinational Forces-Iraq Joint Interagency Task Force-Iraq from September 2008 to October 2009, and participated in other planning efforts as the senior advisor to the USFI Director of Operations through December 2011.

The study, "Ending the U.S. War in Iraq: The Final Transition, Operational Maneuver, and Disestablishment of United States Forces-Iraq," can be found at www.rand.org. Other authors of the study include Charles Ries, Larry Hanauer, Ben Connable, Terrence K. Kelly, Michael J. McNerney, Stephanie Young, Jason H. Campbell and K. Scott McMahon.

Research for the study was sponsored by the United States Forces-Iraq and conducted within the International Security and Defense Policy Center of the RAND National Defense Research Institute, a federally funded research and development center sponsored by the Office of the Secretary of Defense, the Joint Staff, the Unified Combatant Commands, the Navy, the Marine Corps, the defense agencies and the defense intelligence community. 